such as Stephenson's Rocket help us to engage a wide audience. Of course, we also aim to add a deeper and more nuanced understanding, and those who penetrate a little farther into the gallery find an exactly parallel (and very popular) timeline display on the technology of everyday life - familiar and once-familiar artefacts that have earned a presence through use at home, in the workplace and at play.

Icons of invention do exist in our imaginations, but Edgerton seems unprepared to accept that humans navigate their culture by identifying exceptional events and discontinuities. Nor is he concerned with exploring the intriguing mental and cultural processes that make certain inventions or episodes memorable and emblematic. But this is not to deny the great importance, and the interest, of what he has started here.

Ultimately, the pursuit of a more global or democratic history is not unproblematic. What would a use-based history of technology be like, and how would it be more than a natural history? It would not be a replacement for other accounts, perhaps, but one running in parallel.

Finally, there is more to understanding than argument alone, and the author is often most persuasive when he is, perhaps unknowingly, being impressionistic and descriptive. One passage in particular was especially evocative and, almost in itself, seemed to validate the whole historiographic attempt: "Travelling through the poor world it is hard to miss... tiny metal-working shops where the most complex bit of machinery may well be an oxyacetylene, or electric, torch for welding." It is from such shops that "at dusk, bright intermittent light from welding illuminates streets all over the world."

Andrew Nahum is principal curator of technology and engineering at the Science Museum, Exhibition Road, London SW7 2DD, UK.

\title{
The fall of a wonder drug
}

\section{Penicillin: Triumph and Tragedy \\ by Robert Bud \\ Oxford University Press: 2007. 344 pp. $£ 30, \$ 55$}

\section{Hugh Pennington}

Alexander Fleming discovered penicillin in September 1928. He sent his initial observations to the British Journal of Experimental Pathology on 10 May 1929 and they were published a month later. The paper made little impact. It is very different now, of course. Antiquarian booksellers salivate at the thought of a copy and value it not far short of the price of a first edition of a James Bond book by another Fleming.

The circumstances surrounding the discovery of penicillin have been described many times. Most accounts are celebratory, some hagiographic. The best one, which is neither, is Ronald Hare's The Birth of Penicillin and the Disarming of Microbes (Allen \& Unwin, 1970). Hare was there, in the Inoculation Department of St Mary's Hospital in London, when Fleming made his discovery.

Robert Bud's book Penicillin is the sequel to Fleming's story and is far from celebratory. The development of antibiotic resistance gets more space than tales of therapeutic success; these are the tragedy and triumph of its subtitle. A major theme is penicillin as a brand. Driving the book is the notion that the casting of penicillin as a 'wonder drug' has done more harm than good. The case is persuasive. By the 1950s, penicillin was cheap enough and safe enough to be used freely and on a grand scale by general practitioners and veterinarians, and the perception of its impact caused not only the general public but many medical specialists to imagine they were living in an era that would soon see the end of infectious disease as a public-health problem. Penicillin was given much of the credit for the undoubted decline in infection that had taken place in Europe and North America. But it was the abundantly available clean water for drinking and washing that had seen off cholera, typhoid and typhus.

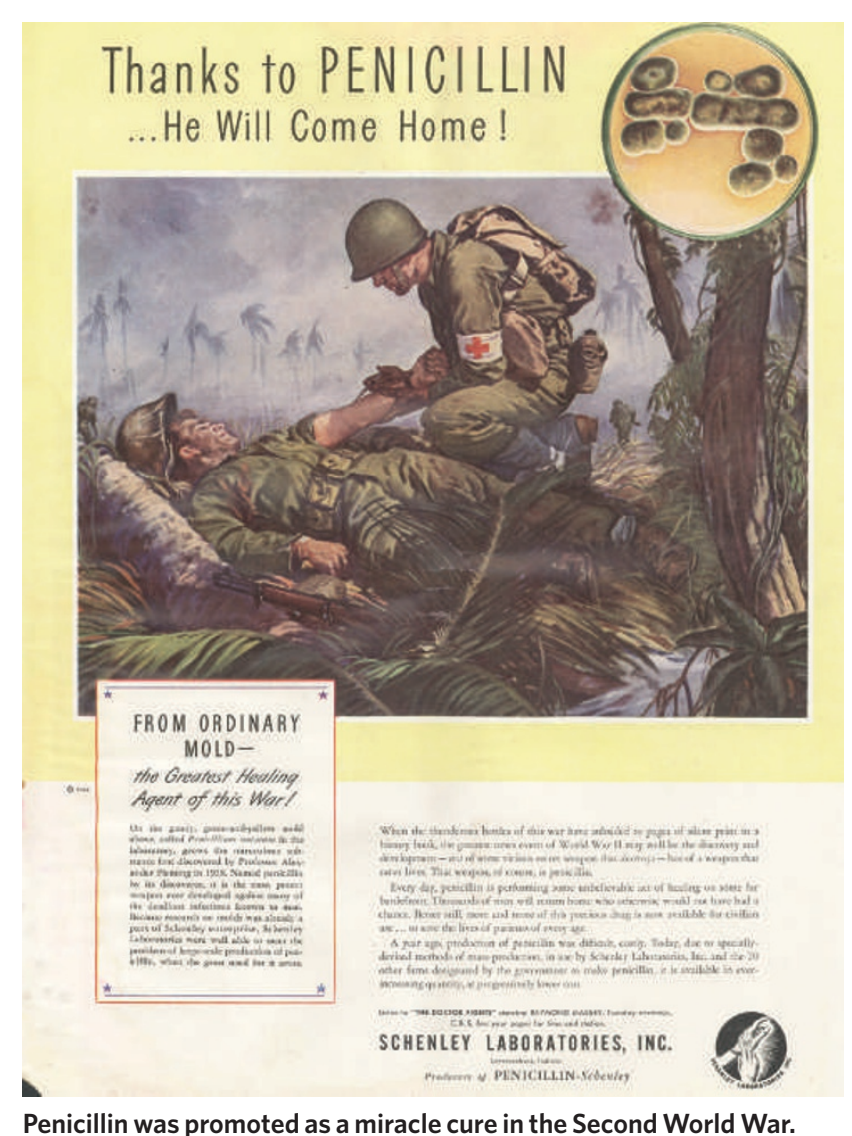

to typify the power of the science that had led to the Anglo-American victory. But he also covers the controversies: how influential politicians, journalists and newspaper owners canonized Fleming, rather than Howard Florey, who led the team that turned penicillin into a drug; and how penicillin joined the Frisch-Peierls memorandum on the manufacture of the atomic bomb and the cavity magnetron as British scientific achievements from which it could be said that the Americans had unreasonably benefited. Bud goes on to recount the development of penicillin derivatives designed to deal with resistant bacteria and public policy responses to the same problem. He ends on a pessimistic note: in essence, the strength of the brand has been outmatched by bacterial evolution.

A focus on the people and institutions involved

Better diet was responsible for the decline in tuberculosis that had been going on for a century. Immunization had made smallpox and diphtheria historical diseases. With the benefit of hindsight we can see that the Streptococcus bacterium that caused scarlet fever - an organism particularly susceptible to penicillin - was becoming less virulent on its own. But of course, from the moment penicillin became generally available, profligate prescription began promoting the spread of resistant pathogens.

Bud shows that the creation of penicillin as a brand owed much to the Second World War and that the strength of its image served
- scientists, policy-makers, propagandists, 'big pharma' and governments - gives a story full of human interest that general readers will enjoy. But this is only the half of it. By and large, the microbes are missing, although in fairness that would have needed another volume. The abiding triumph of penicillin over Treponema pallidum, which turned syphilis from a common scourge to a clinical curiosity, and its difficult relationship with Staphylococcus aureus, which was the organism on Fleming's famous Petri dish and continues today as MRSA, are big stories too.

Hugh Pennington is in the School of Medicine, University of Aberdeen, Aberdeen AB9 2ZD, UK. 